\title{
Relação da vegetação de caatinga com a condição geomorfométrica local ${ }^{1}$
}

\author{
$\overline{\text { Polyanna da C. Bispo1,2, Márcio de M. Valeriano2,3 \& Tatiana M. Kuplich }}{ }^{2}$
}

\begin{abstract}
RESUMO
Objetivou-se, com o presente trabalho, avaliar o potencial das variáveis geomorfométricas extraídas de dados SRTM (Shuttle Radar Topographic Mission) para identificação de tipos vegetacionais da Reserva Particular do Patrimônio Natural de Serra das Almas, CE. Em estudo conduzido na escala de 1:100.000, as variáveis geomorfométricas (elevação, declividade, orientação de vertente, curvatura vertical e curvatura horizontal) foram confrontadas com o mapa de vegetação referência, através de análises de histogramas e análises discriminantes. As variáveis mais importantes na distinção entre os tipos vegetacionais, foram a elevação, a declividade e a curvatura vertical, embora se pudesse observar preferências de tipos mapeados em relação às demais variáveis. Apesar dos dados geomorfométricos mostrarem potencial indicativo das classes de vegetação pela interpretação dos padrões, as análises sob abordagem numérica resultaram em discriminação em um nível aquém do detalhamento temático do mapa referência. Concluiu-se que os dados geomorfométricos representaram significativos insumos para o mapeamento fitogeográfico, devendo ser explorados de forma integrada, em complementaridade às demais variáveis já utilizadas.
\end{abstract}

Palavras-chave: topografia, floresta, bioma, SRTM, Serra das Almas

\section{Relationship between Caatinga vegetation and the local geomorphometric condition}

\begin{abstract}
The objective of this work was to assess the potential of geomorphometric variables, derived from SRTM (Shuttle Radar Topographic Mission) data, to help in identifying vegetation types in the Serra das Almas National Park (CE). A 1:100.000 survey vegetation map was used as reference and the geomorphometric variables (elevation, slope, aspect and profile and plan curvatures) were compared to the mapped units. The variables elevation, slope and profile curvature were shown as the most important for their high discrimination power of the vegetation types. Although geomorphometric data had strong potential for characterizing vegetation through map comparisons, the achieved thematic detail levels were under those of the reference map when data was analyzed under a numerical approach. It was concluded that geomorphometric data were important input for vegetation mapping, and should be employed together with currently used data.
\end{abstract}

Key words topography, forest, biome, SRTM, Serra das Almas

\footnotetext{
1 Parte da Dissertação de Mestrado do primeiro autor apresentada ao Instituto Nacional de Pesquisas Espaciais, São José dos Campos, SP. Apoio financeiro CN Pq 2 IN PE, Av dos Astronautas, 1.758, Jd. Granja, CEP 12227-010, São José dos Campos, SP. Fone: (12) 3945-6424. Fax: (12) 3945-6488. E-mails: polyanna@ltid.inpe.br; valerian@Itid.inpe.br; tmk@Itid.inpe.br

3 Bolsista Produtividade do CN Pq
} 


\section{INTRODUÇÃO}

Dados de sensores ópticos a bordo de satélites ou aeronaves fornecem informações sobre o dossel vegetal os quais, com apoio de campo, são usados em mapeamentos diversos. Para o levantamento de dados sobre a vegetação, a utilização de dados espectrais Landsat (Woodcock et al., 1994; Wylie et al., 2002; Colstoun et al., 2003; Cingolani et al., 2004; Espírito Santo et al., 2005) e mais recentemente de dados MODIS (Muchoney et al., 2000; Anderson et al., 2005; Oliveira Júnior \& Shimabukuro, 2005; Shimabukuro et al., 2006; Ferreira et al., 2007), pode ser considerada uma abordagem tradicional dentro desse contexto, dada à profusão deste tipo de estudo. Evidentemente, tais dados têm sua capacidade limitada à medida em que determinadas formações vegetais possuem respostas espectrais semelhantes. Um dos principais projetos que visaram ao mapeamento da cobertura vegetal brasileira, foi o RADAMBRASIL. A variedade de atributos usados no sistema de classificação (Veloso et al., 1991) refletiu a variabilidade estrutural dos tipos de vegetação do Brasil. As informações geradas pelo projeto realçam a importância da topografia na caracterização da paisagem local e regional, já que se trata de um dos fatores determinantes do estabelecimento, distribuição e diversidade de espécies vegetais.

No caso do Bioma Caatinga, os fatores topográficos relacionados à sua vegetação típica ainda são pouco conhecidos, assim, estudos neste sentido são de grande relevância contribuindo para melhor compreensão dos aspectos físicos e naturais dentro do contexto da Caatinga, um dos menos estudados e mais complexos Biomas brasileiros.

Embora se reconheçam os dados topográficos como significativa fonte de informações para subsidiar o mapeamento da vegetação, o estabelecimento de metodologias com este aporte requer o desenvolvimento de estudos específicos para determinar as relações que existem entre ambos os aspectos, condição que pode ser explicada por uma história de ausência de levantamentos topográficos detalhados, pela qual grande parte do território nacional permanece com mapeamentos em escalas inadequadas para várias aplicações. Neste contexto, a utilização de bases topográficas obtidas por sensores orbitais pode, enfim, significar a viabilização de tais estudos. A missão SRTM (Shuttle Radar Topographic Mission), ocorrida em 2000, possibilitou a coleta de dados altimétricos para praticamente toda a superfície terrestre, haja vista que a existência desses dados em cobertura nacional permite que se avalie e se desenvolva seu potencial para o mapeamento da vegetação, de forma relativamente padronizada e em diferentes ambientes.

Os dados SRTM mostraram-se passíveis de derivação em variáveis geomorfométricas, para expressão das diferentes características do relevo, o que resulta em um conjunto de dados em complemento à altimetria. Cada variável condiciona a vegetação através de diferentes aspectos da paisagem (temperatura, exposição solar e hidrologia, por exemplo), além do controle direto sobre o transporte e o acúmulo de estruturas de propagação, biomassa e substâncias vegetais que afetam sua distribuição. Ante o que se tem, o objetivo do pre- sente trabalho é o de avaliar o uso isolado das variáveis geomorfométricas locais extraídas de modelos digitais de elevação SRTM para identificação de tipos vegetacionais do bioma Caatinga utilizando-se, como representante deste bioma, a Reserva Particular do Patrimônio Natural de Serra das Almas (RPPNSA). É com tal propósito que se busca selecionar, neste estudo, as variáveis geomorfométricas que melhor caracterizam os tipos de vegetação e, reciprocamente, identificar as condições geomorfométricas para ocorrência das diferentes classes observadas, cujas análises recairão sobre planos de informação correspondentes às variáveis geomorfométricas e seu confronto com dados de mapeamento de vegetação existentes da Reserva.

\section{MATERIAL E MÉTODOS}

\section{Área de estudo}

Tendo em vista os objetivos da pesquisa, buscou-se selecionar uma área com diversidade topográfica e vegetacional e que dispusesse de um mapeamento da vegetação típica de Caatinga. Deste modo, foi selecionada a Reserva Particular do Patrimônio Natural de Serra das Almas, como área representante do Bioma Caatinga (Figura 1).

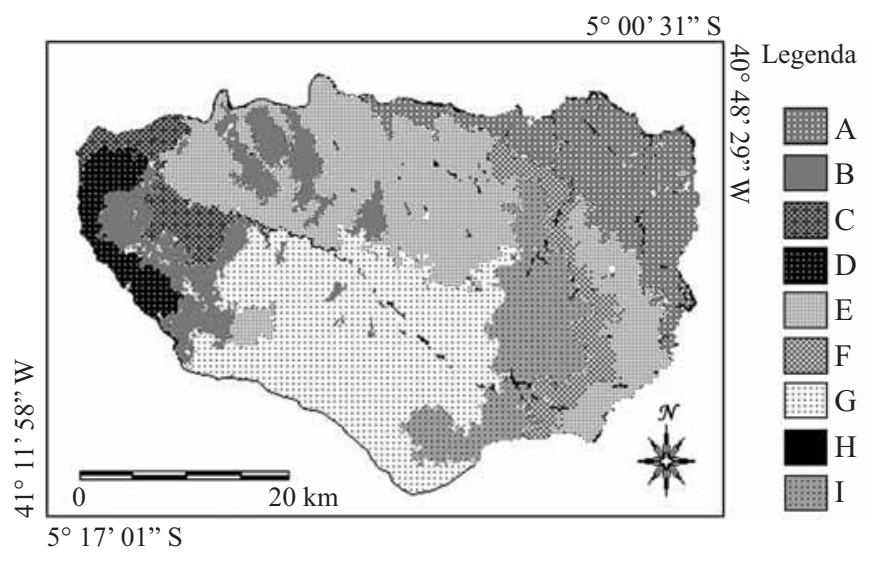

Figura 1. Área de estudo: Mapa de vegetação da Reserva Particular do Patrimônio Natural de Serra das Almas (RPPNSA). Classes de Vegetação: A (Caatinga Arbórea-Arbustiva), B (Complexo Arbóreo), C (Caatinga Herbáceo-Lenhosa), D (Complexo Arbóreo-Arbustivo), E (Caatinga Arbórea), F (Caatinga Florestada), G (Carrasco), H (Complexo Galeria) e I (Mata Seca)

Esta área abrange a Área Prioritária n.6 do PPBIO (Programa de Pesquisa em Biodiversidade do Semiárido) criada em 1998, com aproximadamente 5.244 ha, sendo delimitada pelas coordenadas geográficas $05^{\circ} 00^{\prime}$ a $05^{\circ} 20^{\prime} \mathrm{S}$ e $40^{\circ} 48^{\prime}$ a $41^{\circ} 12^{\prime}$ W, na fronteira entre os Estados do Piauí e Ceará.

O clima da região em que está inserida a RPPNSA, é complexo, devido à presença de diferentes fisionomias de relevo e pela associação de dois sistemas climáticos, formados pelos alísios do Nordeste e do Sudeste, tais condições promovem uma dinâmica sazonal marcada por chuvas em diversos períodos do ano e em diferentes quantidades. O clima varia na região nordeste, desde o superrúmido, com chuvas 
de até $2000 \mathrm{~mm} \mathrm{ano}^{-1}$, até o semiárido, com chuvas entre 300-500 mm ano-1, no qual as chuvas ficam restritas a uns poucos meses durante o ano. Assim, a disponibilidade de água é o fator determinante para a vegetação da região (Carvalho \& Pinheiro Júnior, 2004). Especificamente, na região de Serra das Almas a paisagem é marcada por um clima tropical megatérmico subúmido-úmido $(\mathrm{Ppt}=1002,8 \mathrm{~mm})$ com chuvas de verão-outono e 7 meses secos (Freitas et al., 2005).

A área é considerada uma amostra representativa da Ecorregião Complexo Ibiapaba-Araripe e possui alta importância biológica. Segundo Carvalho \& Pinheiro Júnior (2004) a área possui, como principais fitofisionomias, Mata Seca, Carrasco, Caatinga Florestada, Caatinga Arbórea, Caatinga Arbórea-Arbustiva, Caatinga Herbáceo-Lenhosa, Complexo Galeria, Complexo Arbóreo e Complexo Arbóreo-Arbustivo.

\section{Dados vegetacionais e topográficos}

O mapa da vegetação da Reserva Particular do Patrimônio Natural de Serra das Almas utilizado no presente estudo possui escala de 1:100.000 (Carvalho \& Pinheiro Júnior, 2004) e foi obtido por meio da identificação de classes de vegetação com base em imagens orbitais TM/Landsat e atividades de campo. A metodologia aplicada envolveu o processo de classificação por segmentação por regiões, interpretação visual e caracterização florístico-fisionômica em campo. As classes temáticas que não puderam ser identificadas no campo e apresentaram padrões individualizados nas imagens orbitais, receberam uma denominação diferenciadora como Complexos vegetais.

Os dados topográficos provieram do banco de dados geomorfométricos TOPODATA (Valeriano, 2005), preparados conforme os procedimentos estabelecidos nesta iniciativa. Os dados SRTM usados correspondem àqueles originalmente disponibilizados para a América do Sul, em meados de 2003, conhecidos como "versão 1". Os dados SRTM das áreas selecionadas foram refinados de 3" para 1" com krigagem e em seguida derivados em variáveis geomorfométricas através de diferentes operações de vizinhança (Valeriano et al., 2006). Derivaram-se, daí, as seguintes variáveis: declividade $(\mathrm{G})$, orientação de vertentes $(A)$, curvatura vertical $\left(\mathrm{k}_{\mathrm{v}}\right)$ e curvatura horizontal $\left(k_{h}\right)$, além da própria elevação $(h)$, para área de estudo. A variável elevação corresponde à altitude do terreno e está relacionada à distribuição altitudinal do solo e clima, condicionando diferentes padrões vegetacionais na paisagem; a declividade, por sua vez, corresponde ao ângulo de inclinação da superfície local, possui ação direta sobre o equilíbrio entre a infiltração de água no solo e escoamento superficial, além de controlar a intensidade dos fluxos de matéria e insolação; a orientação de vertentes corresponde ao alinhamento do terreno em relação ao sol, geralmente expressa em azimute e relaciona-se ao grau de sombreamento do terreno controlando a direção dos fluxos de matéria e insolação, portanto, com efeitos locais sobre os regimes hídricos e de energia. Este conjunto de fatores resulta na formação de ambientes com diferentes características físicas e biológicas, as quais permitem o estabelecimento de diferentes tipos de vegetação; a curvatura vertical se refere ao caráter convexo/côncavo do terreno quando analisado em perfil; e finalmente a curvatura horizontal, se que refere ao caráter divergente/convergente dos fluxos de matéria sobre o terreno quando analisado em projeção horizontal. As duas últimas variáveis estão relacionadas aos processos de migração e acúmulo de água, minerais e materiais orgânicos no solo através da superfície, proporcionados pela gravidade, exercendo influência indireta sobre a vegetação local (Schmidt et al., 2003).

O geoprocessamento foi realizado no Idrisi versão 2.0 (Eastman, 1998) e as análises estatísticas conduzidas no Statistica 6.0 (StatSoft, 2001).

\section{Amostragem e análise dos dados}

Após a seleção do mapa de vegetação foram feitas a migração e a compatibilização desses dados com os dados geomorfométricos e uma amostragem das variáveis por classe vegetacional em esquema aleatório estratificado e se definiram diferentes densidades de amostragem para que fossem escolhidos aproximadamente 50 pontos de cada classe. Os dados amostrados foram pareados em planilhas, de acordo com sua posição geográfica e o conteúdo dessas planilhas submetido às análises estatísticas.

Os planos de informação armazenados foram editados na forma de mapas uniformizados para uma visualização conjunta dos dados. Histogramas das variáveis geomorfométricas foram elaborados dentro da área de cada classe de vegetação, buscando-se identificar grupos de classes de comportamento semelhantes e variáveis de maior poder indicativo dos mesmos.

Verificou-se a separabilidade estatística das classes de vegetação com base nas variáveis geomorfométricas, através de análises discriminantes (Manly, 1994). Fez-se a aplicação das análises após se agrupar classes de vegetação com estruturas semelhantes que, no mapa de referência, estavam muito particularizadas. Essas análises foram aplicadas também dentro dos grupos vegetacionais formados por mais de duas subfisionomias, com o intuito de avaliar o uso das variáveis geomorfométricas como indicadores de classes no nível das subfisionomias vegetais. Para melhorar a linearidade dos dados, estes foram logaritmizados e posteriormente padronizados.

As novas classes de vegetação formadas a partir do reagrupamento dos dados de vegetação originais correspondem a grupos vegetacionais: Complexo Arbóreo-Arbustivo (Classes agrupadas: Caatinga Arbóreo-arbustiva (A); Caatinga Herbáceo-Lenhosa (C); Complexo Arbóreo-Arbustivo (D)), Complexo Arbóreo (Classes agrupadas: Complexo Arbóreo (B); Caatinga Arbórea (E); Caatinga Florestada (F)), Carrasco, Complexo Galeria e Mata Seca.

Visando avaliar o potencial de aplicação dos dados geomorfométricos no mapeamento da vegetação, realizaram-se processamentos que tiveram, como base, as observações gerais e os resultados das análises estatísticas.

As análises discriminantes aplicadas sobre as classes vegetacionais reagrupadas, assim como dentro dos grupos que incluíam mais de duas subfisionomias, indicaram as variáveis geomorfométricas de maior peso na separação dos grupos, bem como quais desses grupos melhor se separavam 
entre si. Os planos de informação das variáveis geomorfométricas foram operados com a equação da primeira função discriminante (na qual a maior parte da variação dos dados se concentrou), resultando em uma nova imagem, referente a esta função. Um mapa experimental de vegetação foi gerado a partir de classificações por fatiamentos, aplicadas sobre esta imagem. O mapa gerado foi editado em comparação com os dados de vegetação agrupados sob as novas classes, em função das similaridades observadas.

\section{RESULTADOS E DISCUSSÃO}

\section{Caracterização da vegetação considerando-se as variáveis geomorfométricas}

Pode-se observar, na apreciação inicial dos dados, as faixas de amplitude numérica dos dados topográficos (Figura 2), além da distribuição geográfica de cada variável. Da apreciação geral dos mapas, notaram-se variações de frequência das variáveis geomorfométricas compatíveis com a distribuição espacial das classes de vegetação (Figura 1).

É possível verificar a correspondência entre determinados padrões topográficos e algumas classes de vegetação. Outras classes se mostraram condicionadas pela elevação, como a Caatinga Arbórea-Arbustiva (A) e a Caatinga Herbáceo-Lenhosa (C), restritas aos terrenos mais baixos, assim
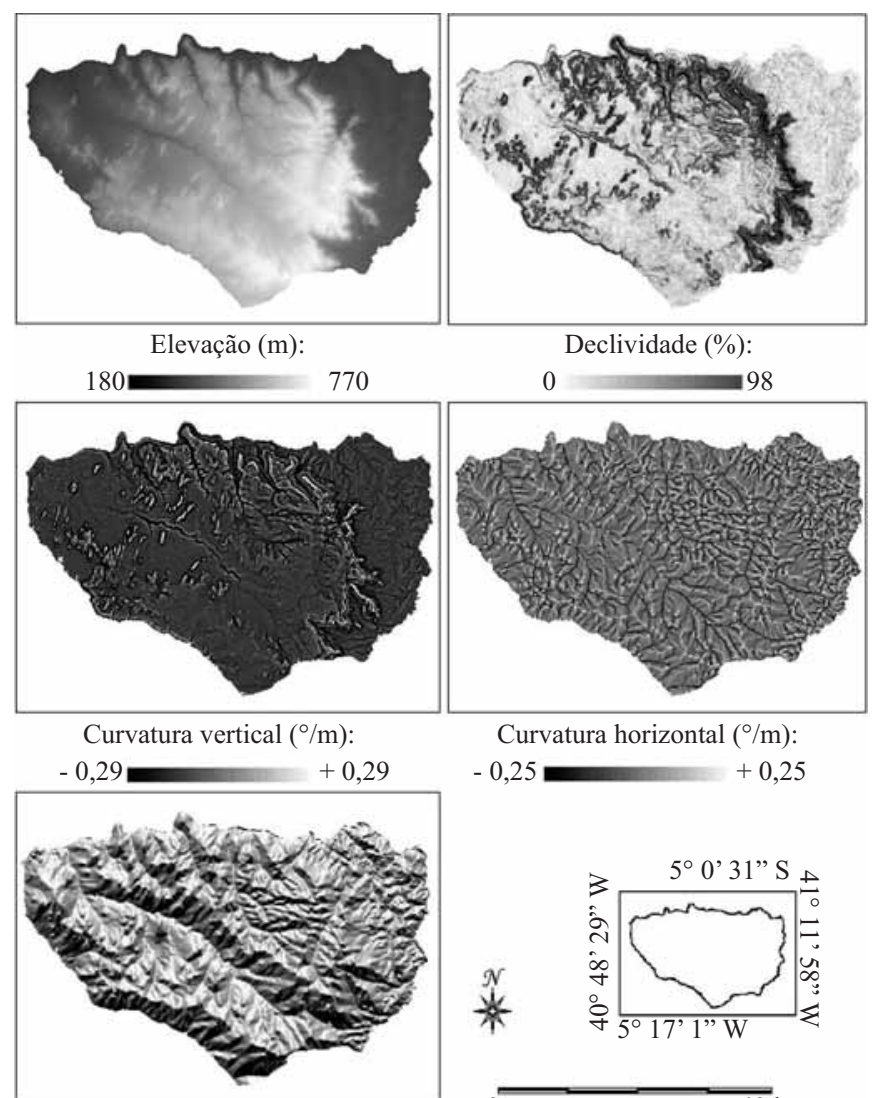

Orientação de vertente $\left(^{\circ}\right)$ :

Curvatura horizontal $(\% / \mathrm{m})$ :



0

360

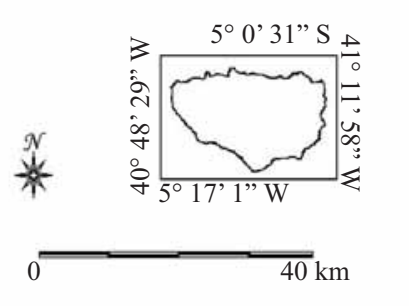

Figura 2. Mapas das variáveis geomorfométricas locais derivadas dos dados SRTM como as classes Complexo Arbóreo (B), Mata Seca (I) e Caatinga Florestada $(\mathrm{F})$, restritas às maiores altitudes. As manchas de Complexo Arbóreo (B) estiveram sempre em topos de elevações locais, com altitudes absolutas relativamente variadas. Os mapas sugerem que a declividade condiciona a Caatinga Florestada (F), que se mostra associada à faixa íngreme que delimita a região de baixio no leste da área. As demais classes condicionadas pela elevação (A, C, B e I) estão parcialmente associadas a baixas declividades de maneira indireta, sempre que os respectivos estratos altitudinais correspondem a terrenos planos.

A relação entre as classes de vegetação e a orientação de vertentes não se mostrou evidente pela comparação entre os mapas. Espera-se, entretanto, que classes de áreas diminutas e únicas tendam a se posicionar numa situação particular de orientação, o que pode causar uma falsa sugestão de controle pela variável, situação em que se encontra a Caatinga Florestada, que se distribui nas faixas íngremes de uma única encosta, resultando em uma restrição indireta da orientação de vertente.

A curvatura vertical mostrou-se uma variável organizada em regiões (manchas), em um padrão definido por convexidades e concavidades distribuídas sobre diferentes segmentos de matrizes relativamente retilíneas. Além da mancha de Caatinga Florestada (F) ao longo da convexidade que corresponde à faixa íngreme descrita anteriormente, observouse que todas as ocorrências de Complexo Arbóreo (B) estiveram associadas a convexidades do terreno. Esta associação é caracterizada pela notável semelhança entre as pequenas manchas desta formação e o formato de feições convexas (na porção central), assim como a delimitação de suas bordas por concavidades (ao norte). Outras convexidades são ocupadas por Catinga Arbórea (E), Carrasco (G) e Mata Seca (I), que têm ampla distribuição por terrenos variados. Por outro lado, nenhuma convexidade foi observada sob as manchas de Caatinga Arbórea-Arbustiva (A), Caatinga Herbáceo-Lenhosa (C), Complexo Arbóreo-Arbustivo (D) e Complexo Galeria (H). Dado que convexidades correspondem, geralmente, a solos mais rasos, mais arenosos e de menor retenção de água (Moore et al., 1993), tal condição na área de estudo mostrou restrição suficiente para impedir a ocorrência dessas formações.

A única formação que se mostrou restrita a concavidades, foi o Complexo Galeria (H), porém esta é uma associação aparente, ou indireta, pois está, por definição e de fato, associada a canais de drenagem. No caso particular do relevo desta área, a derivação do MDE (Modelo Digital de Elevação) evidenciou a drenagem como concavidade, porém pode haver áreas com outro padrão de curvatura vertical. Canais de drenagem são mais apropriadamente evidenciados pela curvatura horizontal, caracterizados como terrenos convergentes (curvatura negativa). Observa-se que o Complexo Galeria se distribui em manchas descontínuas ao longo do curso dos principais rios, com maior frequência nos trechos em que o canal tem baixa declividade.

A Figura 3 mostra a distribuição de frequência relativa das variáveis geomorfométricas dentro de cada classe de vegetação em comparação com toda a área da RPPNSA. A diferença 

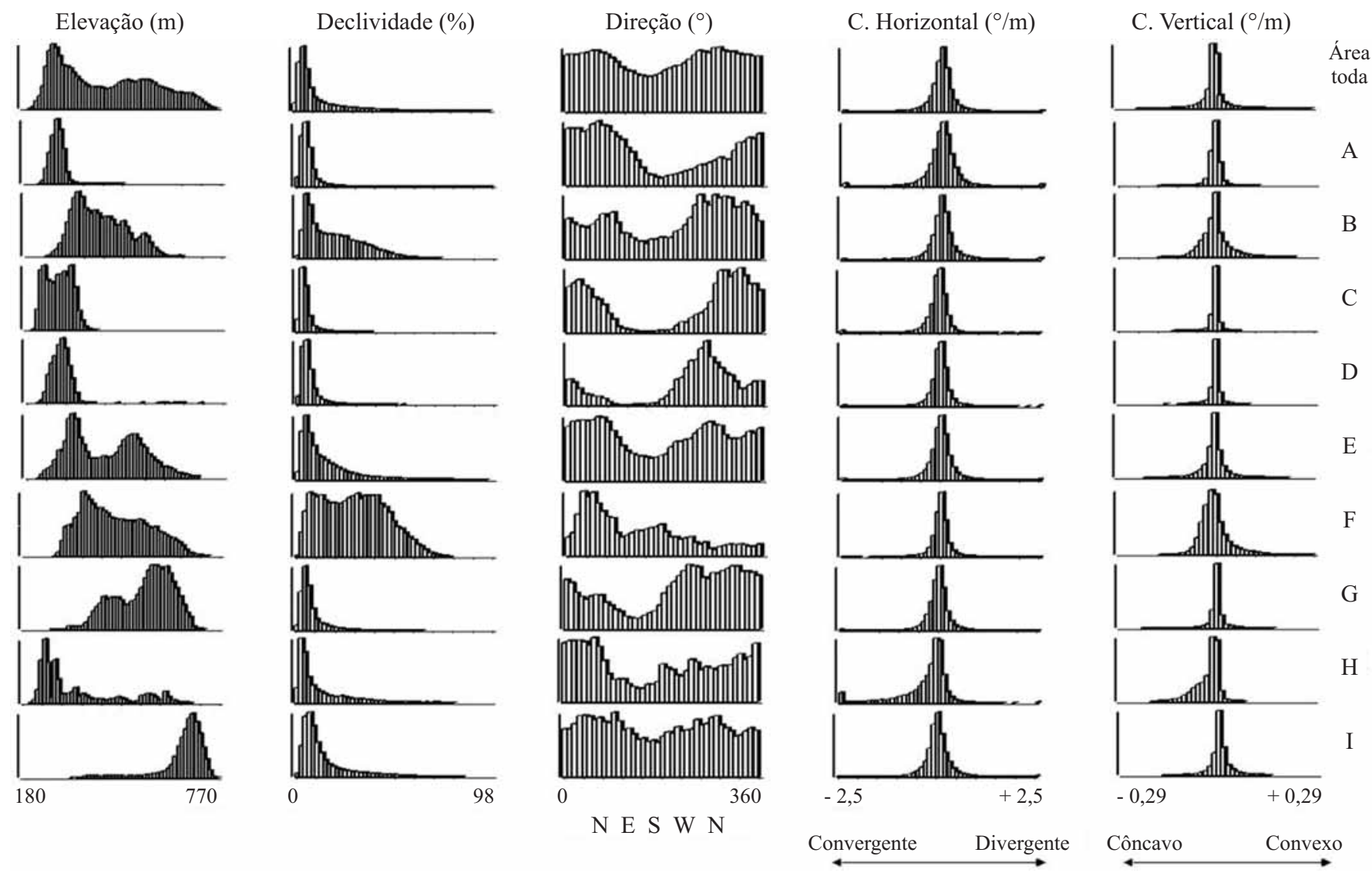

Figura 3. Distribuição de frequência (f) das variáveis topográficas na totalidade da RPPN SA e nas suas classes de vegetação: A (Caatinga Arbórea-Arbustiva), B (Complexo Arbóreo), C (Caatinga Herbáceo-Lenhosa), D (Complexo Arbóreo-Arbustivo), E (Caatinga Arbórea), F (Caatinga Florestada), G (Carrasco), H (Complexo Galeria) e I (Mata Seca)

de distribuição das frequências de cada classe de vegetação e da RPPNSA, revela as preferências de cada tipo vegetacional a determinadas condições topográficas (Figura 3).

Os histogramas confirmaram a Caatinga Arbórea-Arbustiva (A) e Caatinga Herbáceo-Lenhosa (C) como classes restritas às áreas de menor elevação. Reciprocamente, confirmam os histogramas Complexo Arbóreo (B), Caatinga Florestada (F) e Mata Seca (I) como formações que não ocorrem nessas condições, embora somente a última apresente clara preferência (isto é, moda) nas altitudes maiores. A formação Carrasco (G) também tem sua moda principal em elevações relativamente altas mas não isoladamente, em razão de uma segunda moda pouco abaixo. As formações Complexo Arbóreo (B) e Complexo Galeria (H), uma vez associadas a convexidades e convergências (Figuras 1 e 2), respectivamente, têm distribuição polimodal da elevação, em função das altitudes de ocorrência dessas curvaturas.

Observa-se que as formações com frequências relativamente mais altas em áreas de maior declividade (Complexo Arbóreo (B), Caatinga Arbórea (E) e Caatinga Florestada (F)) se distribuem em uma faixa intermediária da amplitude altimétrica da área e correspondem também às maiores dispersões de curvatura vertical, em confirmação da relação entre declividades e as variações de curvatura. A formação Carrasco (G) tem a mesma distribuição altimétrica concentrada, no entanto, em áreas de pequena declividade e curvaturas. As altas declividades desta classe cor- respondem à transição entre os dois estratos altimétricos da grande mancha central, expressa nas duas modas na distribuição da elevação.

Embora a comparação de mapas mostrasse notáveis relações, principalmente, entre algumas classes e a curvatura vertical, os histogramas das curvaturas indicam a dificuldade de aplicação analítica dessas variáveis na classificação da vegetação. A simetria da distribuição das duas curvaturas (horizontal e vertical) é uma característica dessas variáveis, independente do tipo de relevo (Valeriano, 2003; Valeriano \& Carvalho Júnior, 2003). Ocasionalmente, podem ocorrer variações de dispersão, sobretudo da curvatura vertical, maior em terrenos mais movimentados porém com distribuição sempre simétrica e centrada em torno do valor nulo. As formações Complexo Arbóreo (B), Caatinga Arbórea (E) e Caatinga Florestada (F) apresentaram maior dispersão de curvatura vertical, coerentemente com a maior frequência de declividades altas, sobretudo a última. As únicas assimetrias notáveis nas distribuições de curvaturas ocorreram no Complexo Galeria, em virtude da sua associação com canais de drenagem; tal característica implica na predominância de terrenos convergentes (horizontalmente) que, no caso local, se mostraram correlatos a concavidades (verticalmente). Assim, ambos histogramas têm maiores frequências em seu lado esquerdo.

Da observação conjunta dos histogramas de todas as classes, verifica-se que as preferências ecofisiológicas das 
diferentes classes de vegetação, quando expressas, estão representadas pela concentração de frequência das variáveis geomorfométricas. Entretanto e mesmo entre as classes de maior contraste geomorfométrico, as distribuições apresentam amplitudes sobrepostas, com raros casos de condições excludentes.

\section{Análises discriminantes}

As análises foram empregadas diante do agrupamento de classes vegetacionais segundo a estrutura de sua vegetação. Desta forma se geraram novos mapas de vegetação referência.

A análise discriminante foi significativa na separação dos grupos vegetacionais com base nas variáveis geomorfométricas (Wilks’ Lambda = 0,20056; F $(20,1437)=44,781$; $\mathrm{p}<0,0000)$; as maiores significâncias na construção do modelo foram as variáveis elevação (h), declividade (G), curvatura vertical $\left(\mathrm{k}_{\mathrm{v}}\right)$ com Wilks' lambdas de 0,6637, 0,2595 e 0,2088 respectivamente. A seleção de tais variáveis condiz com as principais características da área de estudo retratadas pelo Projeto RADAMBRASIL (1981) segundo o qual a região de Serra das Almas é constituída por feições morfológicas de topos planos, expressas por interflúvios tabulares evidenciando-se, com menor frequência áreas de relevos convexizados e aguçados, além de alguns residuais isolados, com declividade e elevação bastante variáveis.

Com relação à distância entre os centróides (Distância de Mahalanobis) dos grupos no espaço discriminante, todas foram estatisticamente significativas. Constatou-se que os grupos mais distantes entre si foram a Mata Seca (I) e o Complexo Arbóreo-Arbustivo (D) (22,4442). A evidente separação entre essas feições é devida, dentre outros fatores, à ocorrência da Mata Seca (composta por vegetação caducifólia, sendo tipo vegetacional correspondente à Floresta Estacional Decidual Montana) estar restrita aos relevos mais altos e ao Complexo Arbóreo-Arbustivo em ocupar as partes mais baixas (Figura 3), resultado este também encontrado por Freitas et al. (2005). Segundo os autores, a Mata Seca é característica de relevo plano a suavemente ondulado em altitudes mais elevadas (maiores que $600 \mathrm{~m}$ ), porém em área com menores amplitudes e aprofundamento de drenagem. Neste ambiente dominam os Latossolos Vermelho-Amarelos álicos. O Complexo Arbóreo-Arbustivo (D), cobertura vegetal variada com misturas desiguais de árvores, arbustos e plantas herbáceas, correspondente à Savana-Estépica arborizada (IBGE, 1992) ocupou relevo de plano a suavemente ondulado em topos planos com menos de $300 \mathrm{~m}$ de altitude (Figura 3), o que condiz com a literatura, em que tal tipo vegetacional é descrito como comum em interflúvios de média a alta amplitude, fraca intensidade de aprofundamento de drenagem e nos Neossolos Quaternários ou Latossolos Vermelho-Amarelos álicos (Carvalho \& Pinheiro Júnior, 2004; Freitas et al., 2005). Deste modo, pode-se observar que a evidente distinção entre as duas fisionomias, Mata Seca (I) e o Complexo Arbóreo-Arbustivo (D) está relacionada a fatores físicos condicionantes dos tipos vegetacionais relacionados à sua ecofisiologia (RADAMBRASIL, 1981). As fisionomias Mata Seca (I) e Carrasco (G) ocupam relevos relativamente semelhantes, áreas mais altas e planas com altitudes em torno de 450 a 650 m (Carvalho \& Freitas 2005; Freitas et al., 2005). Além disso, apresentam semelhanças quanto ao comportamento caducifólio com indivíduos despidos de folhagem nos períodos secos (Carvalho \& Pinheiro Júnior, 2004). Neste contexto e apesar da distância entre os relevos dessas duas fisionomias ter sido significativa (Distância de Mahalanobis = 1,5407), estes foram os grupos mais próximos entre si, indicando que, entre os tipos de vegetação considerados, a Mata Seca (I) e o Carrasco (G) foram os que ocorreram em relevos menos distintos.

Quanto aos processamentos baseados nas análises discriminantes, a geração da imagem da primeira função discriminante de cada área permitiu a obtenção de uma classificação experimental (Figura 4), obtida através do fatiamento da função 1. Este foi realizado em de intervalos gerados a partir da análise de histograma da imagem da primeira função discriminante. O mapa de vegetação referência, aqui apresentado, é produto de um reagrupamento de classes de vegetação em função da semelhança entre suas estruturas vegetacionais. É possível observar, no mapa da função 1, padrões comparáveis às classes de vegetação.

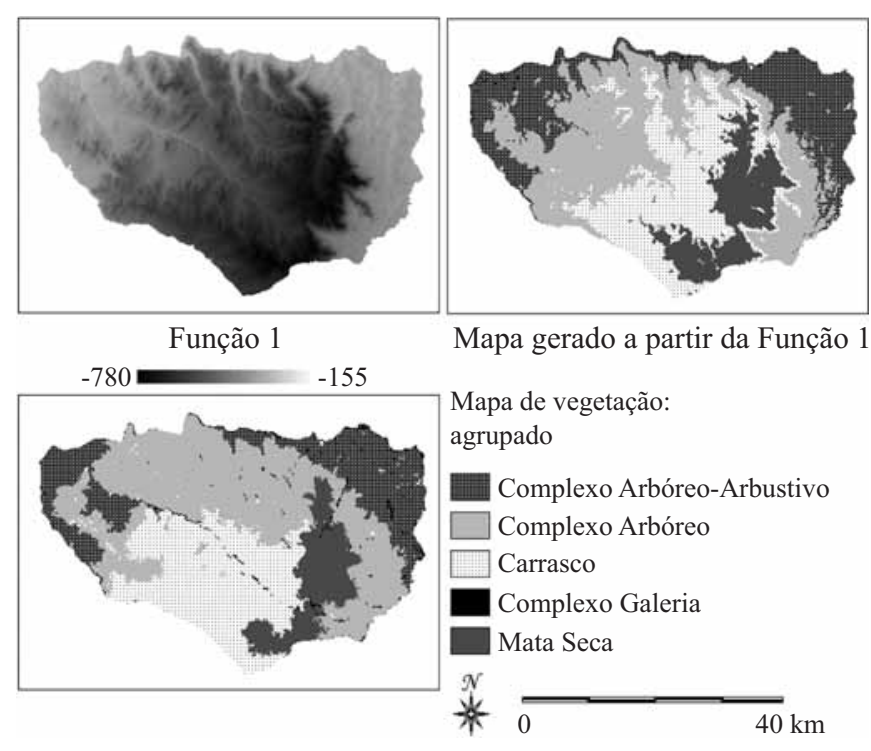

Figura 4. Imagens da Função discriminante 1, Classificação por Fatiamento da Função discriminante 1 sobre variáveis geomorfométricas para a Reserva Particular do Patrimônio Natural de Serra das Almas (RPPNS) e Mapa de vegetação agrupada como referência

Fez-se o fatiamento a partir da função 1, o qual mostrouse muito semelhante ao mapa de vegetação, especialmente quanto às classes Complexo Arbóreo-Arbustivo e Mata Seca devido, sobretudo, às dissimilaridades entre esses tipos de feições já citados.

Como o Complexo Arbóreo e o Complexo Arbóreo-Arbustivo apresentaram subfisionomias, foram feitas análises separadas para as mesmas, com o objetivo de verificar o desempenho das variáveis topográficas como preditoras dessas subfisionomias. No que se refere a Complexo Arbóreo, a análise discriminante mostrou-se significativa na separação dos grupos vegetacionais (Complexo Arbóreo, Caatinga 
Arbórea e Caatinga Florestada) com base nas variáveis geomorfométricas (Wilks’ Lambda: 0,78872 F $(8,268)=4,2211$ $\mathrm{p}<0,0001)$. As maiores significâncias na construção do modelo foram as variáveis declividade $(G)$, orientação de vertente $(A)$ e curvatura vertical $\left(\mathrm{k}_{\mathrm{v}}\right)$ com Wilks' Lambda 0,8789, 0,8386 e 0,8101, respectivamente.

A distância entre os centróides dos grupos no espaço discriminante indicou que os grupos mais distantes entre si foram Caatinga Florestada e Caatinga Arbórea (1, 2590). A Caatinga Florestada corresponde à vegetação de transição do tipo Contato Savana-Estépica/Floresta Estacional e ocupa regiões nas encostas, maciços e serras. Segundo Carvalho \& Pinheiro Júnior (2004) e Freitas et al. (2005), a Caatinga Florestada é comum em terrenos com elevações de topos contínuos a aguçados, separados, em geral, com vales em "V", com interflúvio com grau mínimo de grandeza e de grau de aprofundamento de drenagem de muito fraco a fraco. Dominam, neste ambiente, os Solos Podzólicos Vermelho-Amarelo eutróficos. Também de acordo com os autores, este tipo de vegetação ocorre em relevo com forte declividade, variando rapidamente de plano a montanhoso e de altitudes de 400 a $700 \mathrm{~m}$, o que concorda com os resultados encontrados no presente trabalho (Figura 3). Já a Caatinga Arbórea corresponde à Savana Estépica-Florestada (IBGE, 1992) e se caracteriza por árvores dos sertões porém de porte mais elevado, ocorrendo em relevo de suave a ondulado a plano (com altitudes de 300 a $400 \mathrm{~m}$ ), e correspondendo, também, aos resultados encontrados no presente trabalho (Figura 3). Este tipo vegetacional pode ocorrer em Solos Podzólicos Vermelho-Amarelo eutróficos e apresentar, ainda, interflúvios menores, ou seja, de grandes amplitudes, mas de grau muito fraco de aprofundamento de drenagem, podendo até ocorrer em Planossolos Solódicos (Carvalho \& Freitas 2005; Freitas et al., 2005).

Por outro lado, os grupos vegetacionais mais próximos foram Complexo Arbóreo e Caatinga Arbórea (0,3440). Entretanto, esta última não foi significativa indicando que as variáveis geomorfométricas não foram capazes de discriminá-las entre si, em conformidade com as primeiras comparações de mapas.

A Figura 5 ilustra o resultado do Fatiamento das subfisionomias do Complexo Arbóreo na área da RPPNSA. Para este caso, o Fatiamento mostrou confusão entre as classes. Entretanto, este resultado evidenciou tendências das classes subfisionômicas, superestimando a ocorrência de Caatinga Florestada e subestimando as demais classes.

A análise discriminante do Complexo Arbóreo-Arbustivo não se mostrou significativa na avaliação dos grupos vegetacionais incluídos nesta classe (Caatinga Arbórea-arbustiva, Caatinga Herbáceo-Lenhosa e Complexo Arbóreo-Arbustivo) com base nas variáveis geomorfométricas (Wilks' Lambda: 0,95796 F $(4,288)=1,5629$ p $<0,1843$ p > 0,05), sinal de que esses grupos não foram separáveis entre si.

As análises discriminantes mostram dois efeitos favoráveis à separabilidade "geomorfométrica”. Em primeiro lugar, as classes mais detalhadas têm menor expressão territorial, o que dá mais chance para a observação de variações locais, como se observou ser o comportamento típico das derivações geomorfométricas. Unidades de mapeamento de áreas me-

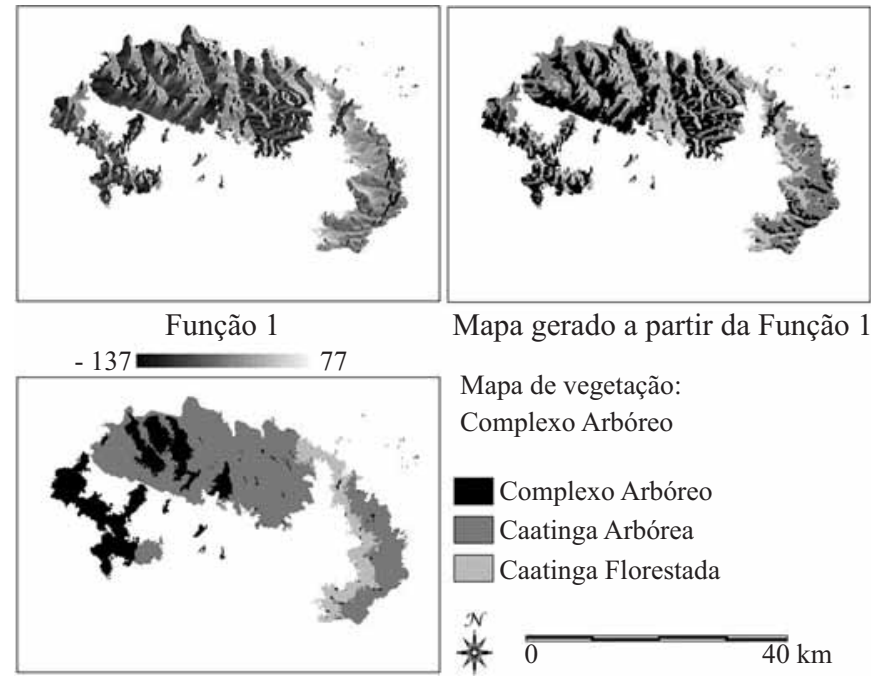

Figura 5. Imagens da Função discriminantes 1, Classificação por Fatiamento da Função discriminante 1 sobre variáveis geomorfométricas para 0 Complexo Arbóreo da Reserva Particular do Patrimônio Natural de Serra das Almas (RPPNSA) e Mapa de vegetação como referência

nores tendem a apresentar distribuições mais concentradas das variáveis, conforme a condição localizada das mesmas. Em segundo, a própria particularização das classes traz mais uniformidade dentro dos grupos vegetacionais, o que pode revelar maior responsividade das mesmas em relação aos fatores do meio físico que influenciam sua distribuição. Em contraposição, unidades mais abrangentes tendem a agrupar formações vegetais com distintas respostas a essas condições além de terem sua distribuição espalhada por áreas maiores e internamente heterogêneas. Como efeito, a distribuição das variáveis geomorfométricas se mostra homogênea entre essas unidades de mapeamento.

\section{CONCLUSÕES}

1. As classes de vegetação mapeadas mostraram-se condicionadas pelas diferentes variáveis geomorfométricas, sobretudo elevação, declividade e curvatura vertical, decorrente da sua correlação com os demais aspectos condicionantes do meio físico (substrato, microclima e hidrologia).

2. Os dados geomorfométricos apresentaram potencial indicativo das classes de vegetação em nível de fitofisionomia, uma vez que estas se caracterizaram por sua preferência (a determinadas condições topográficas), representando significativos insumos para o mapeamento fitogeográfico, devendo ser explorados de forma integrada, em complementaridade às demais variáveis já utilizadas.

\section{AgRADECIMENTOS}

Os autores agradecem a Vitor Celso de Carvalho, pela geração do mapa usado como referência no presente artigo, e a Marcos Wellausen Dias de Freitas, pelo fornecimento dos vetores provenientes deste mapa, para seu processamento neste estudo. 


\section{LITERATURA CITADA}

Anderson, L. O.; Shimabukuro, Y. E.; Lima, A.; Medeiros, J. S. Mapeamento da cobertura da terra do estado do Mato Grosso através da Utilização de dados multitemporais do sensor MODIS. Geografia, v.30, n.2, p.365-380, 2005.

Carvalho, V. C.; Freitas, M. W. D. Abordagem integrada para mapeamento da dinâmica da cobertura da terra em três áreas piloto do bioma Caatinga. In: Simpósio Brasileiro de Sensoriamento Remoto, 12, 2005, Goiânia. Anais... São José dos Campos: INPE, 2005. p.1459-1468.

Carvalho, V. C.; Pinheiro Júnior, O. Mapeamento semidetalhado da cobertura vegetal das áreas de estudo, com uso de sensoriamento remoto e sistema geográfico de informações. São José dos Campos: INPE, 2004. 356p. Relatório Técnico

Cingolani, A. M.; Renison, D.; Zak, M. R.; Cabido, M. R. Mapping vegetation in a heterogeneous mountain rangeland using landsat data: An alternative method to define and classify land-cover units. Remote Sensing of Environment, v.92, n.1, p.84-97, 2004.

Colstoun, E. C. B.; Story, M. H.; Thompson, C.; Commisso, K.; Smith, T. G.; Irons, J. R. National Park vegetation mapping using multitemporal Landsat 7 data and a decision tree classifier. Remote Sensing of Environment, v.85, n.3, p.316-327, 2003.

Eastman, J. R., IDRISI for Windows - User's Guide Version 2.0. Clark University: Worcester, 1998.

Espírito Santo, D. B.; Shimabukuro, Y. E.; Kuplich, T. M. Mapping forest successional stages following deforestation in Brazilian Amazonia using multitemporal Landsat images. International Journal of Remote Sensing, v.26, n.3, p.635-642, 2005.

Ferreira, N. C.; Ferreira, L. G.; Huete, A. R.; Ferreira M. E. An operational deforestation mapping system using MODIS data and spatial context analysis. International Journal of Remote Sensing, v.28, n.2, p.47-62, 2007.

Freitas, M. W. D.; Carvalho, V. C.; Crepani, E.; Medeiros, J. S.; Espig, S. A. Aplicações de geoprocessamento no estudo dos geossistemas e Zoneamento Ecológico - Econômico de Serra das Almas (CE/PI). In: Simpósio Brasileiro de Sensoriamento Remoto, 12., 2005, Goiânia. Anais... São José dos Campos: INPE, 2005. p.2153-2160.

IBGE - Instituto Brasileiro de Geografia e Estatística. Manual técnico da vegetação brasileira. Rio de Janeiro: IBGE, 1992. 92p. Manuais Técnicos em Geociências, 1

Manly, B. F. J. Multivariate statistical metods - a primer. London: Chapman and Hall, 1994. 210p.

Moore, I. D.; Gessler, P. E.; Nielsen, G. A.; Peterson, G. A. Soil attribute prediction using terrain analysis. Soil Science Society of America Journal, v.57, n.2, p.443-452, 1993.

Muchoney, D.; Borak, J.; Chi, H.; Friedl, M.; Gopal, S.; Hodges, J.; Morrow, N.; Strahler, A. Application of the MODIS global supervised classification model to vegetation and land cover mapping of Central America. International Journal of Remote Sensing, v.21, n.6-7, p.1115-1138, 2000.
Oliveira Júnior, H. J.; Shimabukuro, Y. E. Mapeamento da cobertura da terra dos Estados do Goiás e Tocantins utilizando imagens do sensor MODIS. In: Simpósio Brasileiro de Sensoriamento Remoto, 12, 2005, Goiânia. Anais... São José dos Campos: INPE, 2005. p.1641-1648.

RADAMBRASIL - Ministério das Minas e Energia. Secretaria-Geral. Folhas SB.24/25 Jaguaribe/Natal: Geologia, geomorfologia, pedologia, vegetação e uso potencial da terra. Rio de Janeiro: DNPM, 1981. 744p. Levantamento de Recursos Naturais, 23

Schmidt, J.; Evans, I. S.; Brinkmann, J. Comparison of polynomial models for land surface curvature calculation. International Journal of Geographical Information Science, v.17, n.8, p.797-814, 2003.

Shimabukuro, Y. E.; Duarte, V.; Anderson, L. O.; Valeriano, D. M.; Arai, E.; Freitas, R. M.; Rudorff, B. F. T.; Moreira, M. A. Near real time detection of deforestation in the Brazilian Amazon using MODIS imagery. Ambiente e Água, v.1, p.37-47, 2006.

StatSof, Inc. Statistica - data analysis software system, version 6 . http://www.statsoft.com. 8 Mar. 2008

Valeriano, M. M. Curvatura vertical de vertentes em microbacias pela análise de modelos digitais de elevação. Revista Brasileira de Engenharia Agrícola e Ambiental, v.7, n.3, p.539-546, 2003.

Valeriano, M. M. Modelo digital de variáveis morfométricas com dados SRTM para o território nacional: O projeto TOPODATA. In: Simpósio Brasileiro de Sensoriamento Remoto 12, 2005, Goiânia. Anais... São José dos Campos: INPE, 2005. p.3595-3602.

Valeriano, M. M.; Carvalho Júnior, O. A. Geoprocessamento de modelos digitais de elevação para mapeamento da curvatura horizontal em microbacias. Revista Brasileira de Geomorfologia, v.4, n.1, p.17-29, 2003.

Valeriano, M. M.; Kuplich, T. M.; Storino, M.; Amaral, B. D.; Mendes, J. N.; Lima, D. J. Modeling small watersheds in Brazilian Amazônia with Shuttle Radar Topographic Mission - 90m data. Computers e Geosciences, v.32, n.8, p.1169-1181, 2006.

Veloso, H. P.; Rangel Filho, A. L.; Lima, J. C. A. Classificação da vegetação brasileira, adaptada a um sistema universal. Rio de Janeiro: IBGE, 1991.124p.

Woodcock, C. E.; Collins, J. B.; Gopal, S.; Jakabhazy, V. D.; Li, X.; Macomber, S.; Ryherd, S.; Harward, V. J.; Levitan, J.; Wu, Y. Mapping forest vegetation using Landsat TM imagery and a canopy reflectance model. Remote Sensing of Environment, v.50, n.3, p.240-254, 1994.

Wylie, B. K.; Meyer, D. J.; Tieszen, L. L.; Mannel, S. Satellite mapping of surface biophysical parameters at the biome scale over the North American grasslands. A case study. Remote Sensing of Environment, v.79, p.266-278, 2002. 